\title{
Monophosphine Ligands Promote Pd-Catalyzed C-S Cross- Coupling Reactions at Room Temperature with Soluble Bases
}

\author{
Jessica Xu' ${ }^{1}$, Richard Y. Liu ${ }^{1}$, Charles S. Yeung ${ }^{2}$, Stephen L. Buchwald ${ }^{1}$ \\ 1)Department of Chemistry, Massachusetts Institute of Technology, Cambridge, Massachusetts \\ 02139, United States \\ 2)Department of Discovery Chemistry, Merck \& Co., Inc., Boston, Massachusetts 02115, United \\ States
}

\begin{abstract}
The Pd-catalyzed cross-coupling of thiols with aromatic electrophiles is a reliable method for the synthesis of aryl thioethers, which are important compounds for pharmaceutical and agricultural applications. Since thiols and thiolates strongly bind late transition metals, previous research has focused on catalysts supported by chelating, bisphosphine ligands, which were considered less likely to be displaced during the course of the reaction. We show that by using monophosphine ligands instead, more effective catalysis can be achieved. Notably, compared to previous methods, this increased reactivity allows for the use of much lower reaction temperature, soluble bases, and base-sensitive substrates. In contrast to conventional wisdom, our mechanistic data suggest that the extent of displacement of phosphine ligands by thiols is, firstly, not correlated with the ligand bulk or thiol nucleophilicity, and secondly, not predictive of the effectiveness of a given ligand in combination with palladium.
\end{abstract}

\section{Graphical Abstract}

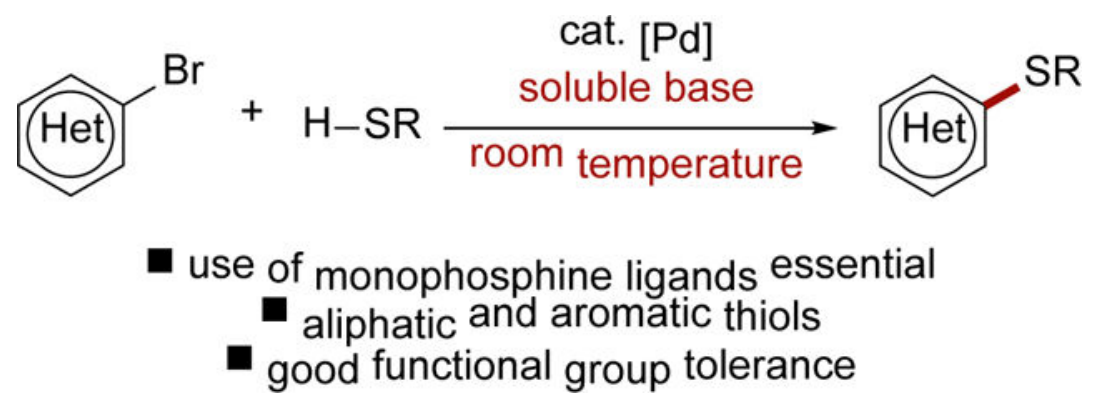

Aryl thioethers and derivatives such as sulfoxides and sulfones are increasingly important classes of molecules in the pharmaceutical industry ${ }^{1}$ and for other applications. ${ }^{2}$ For instance, $S$-aryl fragments are found in marketed drugs that treat schizophrenia (perphenazine), ${ }^{3 \mathrm{a}}$ autoimmune disorders (nelfinavir mesylate), ${ }^{3 \mathrm{~b}}$ rheumatoid arthritis and

Corresponding Authors: Stephen L. Buchwald: sbuchwal@mit.edu, Charles S. Yeung: charles.yeung@merck.com. MIT has filed patents on ligands and precatalysts that are described in this manuscript, from which S.L.B and former/current coworkers receive royalty payments. 
organ rejection (azathioprine), ${ }^{3 \mathrm{c}}$ cancer (axitinib, ${ }^{3 \mathrm{~d}}$ bicalutamide ${ }^{3 \mathrm{e}}$ ), and heart conditions (ticagrelor). ${ }^{3 f}$ Given the availability of thiols and aryl halides or pseudohalides, metalcatalyzed cross-coupling, ${ }^{4,5}$ including Pd-catalyzed C-S coupling in particular, ${ }^{6}$ has emerged as a popular synthetic route to these compounds.

It is well known that each of the elementary steps within the catalytic cycle (see below, Fig. $2 \mathrm{~A}$ ) is associated with a low activation barrier: definitive mechanistic investigations by Hartwig, ${ }^{6 \mathrm{k}}$ as well as reports of relevant stoichiometric reactions involving palladium complexes ${ }^{7}$ indicate that each transformation can take place in seconds or minutes under ambient conditions. Nevertheless, the leading catalytic methods require elevated temperatures (refluxing toluene or dioxane) to obtain synthetically useful yields. This discrepancy is explained by the proclivity of palladium-based catalysts to form off-cycle resting state species in the presence of thiols. Two frequently cited pathways for catalyst deactivation are (1) the formation of unreactive $\mathrm{LPd}(\mathrm{H}) \mathrm{SR}$ or $\left[\mathrm{LPd}(\mathrm{SR})_{2}\right]^{-}$ complexes $^{4 a, 5 a, 6 a, d, h, k}$ and (2) the displacement of the phosphine ligand by the binding of multiple thiolate ligands. ${ }^{4 \mathrm{~b}, 5 \mathrm{a}, 6 \mathrm{~d}, \mathrm{k}, \mathrm{l}, \mathrm{m}}$

Although monophosphine-ligated palladium catalysts have shown exceptionally high reactivity in $\mathrm{C}-\mathrm{C},{ }^{8} \mathrm{C}-\mathrm{N},{ }^{9} \mathrm{C}-\mathrm{O},{ }^{10} \mathrm{C}-\mathrm{F},{ }^{11}$ and $\mathrm{C}-\mathrm{CF}_{3}$ cross-coupling, ${ }^{12}$ they have not yet been successfully applied in the development of $\mathrm{C}-\mathrm{S}$ cross-coupling, which has instead relied primarily on catalysts derived from tightly binding chelating bisphosphine ligands. These ligands are thought to minimize deactivation by nucleophilic thiolate ligands (vide supra). After the pioneering studies of $\mathrm{Pd}\left(\mathrm{PPh}_{3}\right)_{4}$-catalyzed coupling of aryl halides with thiolate anions by Migita, ${ }^{6 \mathrm{n}, 60}$ bidentate phosphines such as SL-J009 ${ }^{6 \mathrm{k}}(\mathbf{L 6})$ and XantPhos $^{6 \mathrm{~m}}(\mathbf{L} 7)$ have emerged as the ligands of choice for this transformation. Other strategies to circumvent phosphine displacement include the usage of an NHC ligand ${ }^{6 \mathrm{p}}$ or employment of a $\mathrm{Pd}^{\mathrm{I}}$ complex as a catalyst ${ }^{6 \mathrm{q}}$. Despite significant advances with regard to minimizing catalyst loading and maximizing turnover numbers, substantial limitations still remain. Foremost, the requirement to employ elevated temperatures renders the reaction conditions incompatible with many functional groups and medicinally important heterocycles. In particular, the combination of high temperature and strong base has been shown to cause significant problems for even mildly base-sensitive substrates, such as indazoles. ${ }^{13}$ Furthermore, the requirement for such substantial energy input is wasteful considering the rapidity of the elementary steps under ambient conditions. Other methods require the pre-formation of sodium thiolate salts ${ }^{6 \mathrm{q}}$ or the complete exclusion of disulfides from the reaction ${ }^{6 \mathrm{p}}$. Finally, the vast majority of $\mathrm{C}-\mathrm{S}$ coupling protocols rely on insoluble, inorganic bases, which pose considerable challenges for miniaturization and for continuous flow applications. In view of the previous successes of biaryl monophosphine-based palladium catalysts in addressing similar issues in related cross-coupling reactions, we considered whether they might be effective for catalytic $\mathrm{C}-\mathrm{S}$ coupling, in spite of concerns regarding thiolate-mediated deactivation.

We selected 4-bromo-1-methylindazole as a model substrate, since $\mathrm{N}$-substituted indazoles and other base-sensitive heterocycles have proved challenging under state-of-the-art C-S cross-coupling conditions. ${ }^{13}$ Although nitrogenous heterocycles such as indazole feature prominently in pharmaceuticals and bioactive natural products, base-mediated Kemp 
elimination is a major side-reaction when strong bases and prolonged heating are required. ${ }^{14}$ In our study, the cross-coupling of this heteroaryl bromide was evaluated with 1-decanethiol in the presence of triethylamine, a soluble, organic base, and a number of oxidative-additioncomplex precatalysts ${ }^{15}$ (P1-P5) derived from monophosphine catalysts developed in our laboratory (for details, see the Supporting Information). Additionally, precatalysts bearing the two most frequently employed bisphosphine ligands, XantPhos (L6) and SL-J009-1 (L7), were also tested.

After two hours at room temperature, the reactions using precatalysts derived from tBuBrettPhos (L2) and tBuXPhos (L4) showed high yields of the desired product (97\% and $100 \%$, respectively). Reactions using complexes of ligands with smaller $P$-Cy groups in lieu of $P$ - $t \mathrm{Bu}$ groups resulted in diminished activity. Notably, at the low temperatures employed, catalysts bearing bisphosphine ligands $(\mathbf{L 6}, \mathbf{L 7})$ failed to deliver useful amounts of the desired product. We also determined that when using a lower catalyst loading $(0.2 \mathrm{~mol} \%)$, tert-butanol is the best solvent for this transformation.

Table 2. Evaluation of catalysts and reaction conditions for Pd-catalyzed aryl thiol arylation. ${ }^{\mathrm{a}}$

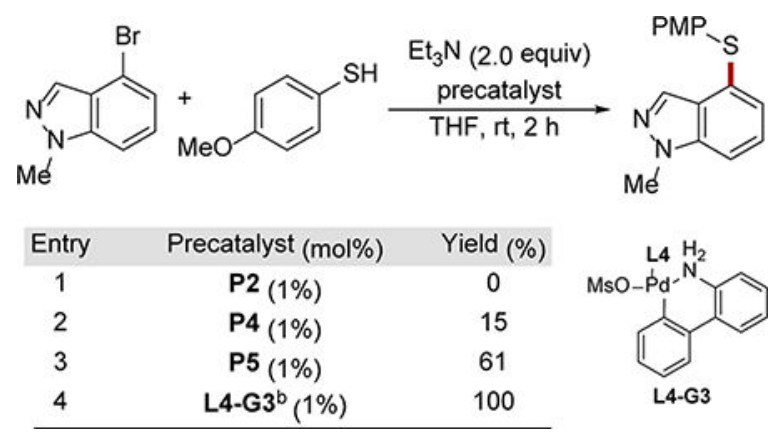

a Conditions: aryl bromide ( $0.1 \mathrm{mmol}, 1.0$ equiv), thiol (1.2 equiv), triethylamine (2.0 equiv), precatalyst (indicated amount) in solvent $(0.20 \mathrm{~mL})$ for $2 \mathrm{~h}$. The yield was determined by calibrated gas chromatography (GC) using dodecane as an internal standard. See the Supporting Information for more details. ${ }^{b}$ Using LHMDS (2.4 equiv) instead of triethylamine. For extended screening data, see table S2 in the Supporting Information.

Aromatic thiols differ significantly from aliphatic thiols in terms of acidity and nucleophilicity. Thus, unsurprisingly, the reaction conditions developed for aliphatic thiols proved to be suboptimal for the reactions of aryl thiols. For these substrates, we evaluated a subset of precatalysts in the coupling of the model aryl bromide with 4-methoxythiophenol. While catalysts based on $\mathbf{L} 2$ and $\mathbf{L} \mathbf{4}$ provided limited yields, the AlPhos(L5)-bound precatalyst provided a promising quantity of the $\mathrm{C}-\mathrm{S}$ coupled product (61\%, Table 2 , entry 5). However, in view of the significant cost differences between tBuBrettPhos (L4) and AlPhos (L5), a similarly effective method using an L4-based precatalyst was desirable. Accordingly, with further optimization, we were able to achieve the same high yield using commercially available L4-G3 by using LHMDS, another soluble base. ${ }^{8 a}$ 
Having discovered efficient conditions for coupling reactions of both aliphatic and aromatic thiols, we examined their scope. First, a variety of aliphatic thiols were efficiently coupled with aryl or heteroaryl bromides, and many common functional groups on either partner were tolerated under the mild reaction conditions. In particular, both 5- and 6-membered heterocycle electrophiles, including an azaindole (2f), a thiophene ( $\mathbf{2 h})$, a benzothiazole (2i), a pyrazole (2j), a thiazole (2l), and a quinoline (2o) were transformed in high yield, regardless of their electronic properties. Notably, many protic substituents are well tolerated, including a phenol (2b), primary aniline (2c), carboxylic acids (2e, 2l), aliphatic alcohols $(\mathbf{2 k}, \mathbf{2 m})$, an amide (2n), and a sulfonamide (2g), without competing $\mathrm{C}-\mathrm{N}$ or $\mathrm{C}-\mathrm{O}$ coupling. For substrates with exceptionally low solubility in tert-butanol, THF can be used as a solvent or co-solvent, and excellent isolated yields are obtained (e.g., $\mathbf{2 f}, \mathbf{2 k}$ ).

The substrate scope of the aromatic thiol coupling was also good. Both electron-rich $(\mathbf{3 b}, \mathbf{3 c})$ and electron-deficient thiols (3f, $\mathbf{3 g}$ ) were arylated in high yields. Heterocyclic partners such as an unprotected indazole (3a), an isoquinoline (3b), and hindered pyridines $(\mathbf{3} \mathbf{j}-\mathbf{3 l} \mathbf{l})$ reacted well under these conditions. Importantly, no background reactions such as nucleophilic aromatic substitution were observed in the absence of palladium or ligand. Again, an aniline (3d) and a phenol (3g) underwent the desired $\mathrm{C}-\mathrm{S}$ coupling transformation without competing $\mathrm{C}-\mathrm{N}$ or $\mathrm{C}-\mathrm{O}$ coupling. Finally, aryl bromides are chemoselectively converted in the presence of aryl chlorides, and thus chloroarene products such as $\mathbf{3 f}$, which are easily derivatized by further cross-coupling, can be produced in high isolated yield.

The effectiveness of these monophosphine catalyst systems raised important mechanistic questions. Historically, it has been assumed that chelating bisphosphine ligands should bind palladium more tightly, and thus, be less prone to thiol(ate)-mediated displacement and deactivation. However, under our conditions (room temperature, soluble base), monophosphine-based catalysts clearly outperformed the state-of-the-art bisphosphine systems. To resolve this discrepancy, we considered the following explanations. First, it was possible that the rate or extent of displacement of a given phosphine from palladium by thiolate ligands did not follow conventional predictions. For instance, perhaps biaryl monophosphine ligands are particularly difficult to displace. Second, the effectiveness of a given catalyst might not be well predicted by the distribution of ligand (Pd-bound or free) in the catalytic resting state.

To examine these hypotheses, we needed to establish the resting state of various catalysts during the steady-state portion of the catalytic reaction. Using NMR spectroscopy, we followed reactions using precatalysts derived from L1-L7 under conditions similar to the optimal reaction conditions, except with slightly elevated catalyst loading for more accurate detection of intermediates. We measured the steady-state distribution of the ligand using ${ }^{31} \mathrm{P}$ NMR measurements made during the course of the coupling reaction.

In the coupling of aliphatic thiols, contrary to our expectations, free ligand was not observed in any case, except when a precatalyst based on $\mathbf{L 1}$ was used. This indicated that, at least at room temperature and with only a weak base present, displacement of the phosphine ligand by alkyl thiolate(s) is not a significant problem for either mono- or bisphosphine ligands. Consistent with previous studies, the failure of bisphosphine ligands $\mathbf{L 6}$ and $\mathbf{L 7}$ to form 
efficient catalysts under these reaction conditions is not due to phosphine displacement, but rather due to the formation of alternative, stable off-cycle species: a $\mathrm{L}_{2} \mathrm{Pd}$ dimer in the case of $\mathbf{L 6}$, and a hydridopalladium thiolate in the case of $\mathbf{L} 7 .^{6 \mathrm{~h}}$

The analogous experiments using aromatic thiols further underscore the difficulty of predicting the steady-state ligand distribution in these coupling reactions. In these cases, most ligands were observed to be in their unbound form during the course of the reaction. Surprisingly, XantPhos (L6), a bisphosphine ligand, was entirely unbound in its resting state, while L5, the most sterically hindered monophosphine ligand, remained partially Pd-bound. Finally, these data again caution against inferring the competency of catalysts from their resting state - for instance, in the case of the catalysts derived from $\mathbf{L 2}$ and $\mathbf{L 4}$, although the phosphine appears to completely dissociate during the reaction, the desired arylation was still observed.

In summary, we have found that certain biaryl monophosphine ligands form exceptionally effective catalysts that promote $\mathrm{C}-\mathrm{S}$ coupling reactions under mild conditions, with soluble bases, and in the presence of many useful functional groups. These catalysts are sufficiently active that they promote thioether formation even when no phosphine-bound palladium species is observable by NMR.

\section{Supplementary Material}

Refer to Web version on PubMed Central for supplementary material.

\section{ACKNOWLEDGMENT}

Research reported in this publication was supported by the National Institute of General Medical Sciences of the National Institutes of Health under Award Number R35GM122483. The content is solely the responsibility of the authors and does not necessarily represent the official views of the National Institutes of Health. We thank Dr. Tony Siu (Merck), Dr. Brett A. Hopkins (Merck), Dr. Scott McCann (MIT), Dr. Andy Thomas (MIT), and Dr. Christine Nguyen (MIT) for advice on the preparation of this manuscript. We thank Jacob M. Ganley (Merck) for assistance with preliminary experiments.

We are grateful to Sigma-Aldrich for gifts of ligands (XPhos, BrettPhos, tBuXPhos, tBuBrettPhos) and Solvias for a gift of the CyPF-tBu used in our research. We thank Rosina Ayore (Merck) and Wilfredo Pinto (Merck) for collecting HRMS data of aryl thioether products.

\section{REFERENCES}

(1). For a review, see:Feng M; Tang B; Liang SH; Jiang X Sulfur Containing Scaffolds in Drugs: Synthesis and Application in Medicinal Chemistry. Curr. Top. Med. Chem 2016, 16, 1200-1216. [PubMed: 26369815]

(2). (a)Thuillier A; Metzner P Sulfur Reagents in Organic Synthesis; Academic Press: New York, 1994.(b)Bernardi F; Csizmadia IG; Mangini A Organic Sulfur Chemistry Theoretical and Experimental Advances; Elsevier: Amsterdam, The Netherlands, 1985; Vol. 19.(c)Rayner CM. Advances in Sulfur Chemistry, Vol. 2; JAI Press: Greenwich, CT, 2000.

(3). (a)Rees LC Chlorpromazine and Allied Phenothiazine Derivatives. Br. Med. J 1960, 2, 522-525. [PubMed: 14436902] (b)Kaldor SW; Kalish VJ; Davies JF II; Shetty BV; Fritz JE; Appelt K; Burgess JA; Campanale KM; Chirgadze NY; Clawson DK; Dressman BA; Hatch SD; Khalil DA; Kosa MB; Lubbehusen PP; Muesing MA; Patick AK; Reich SH; Su KS; Tatlock JH Viracept (Nelfinavir Mesylate, AG1343): A Potent, Orally Bioavailable Inhibitor of HIV-1 Protease. J. Med. Chem 1997, 40, 3979-3985. [PubMed: 9397180] (c)Azathioprine, Azathioprine Sodium In 
AHFS Drug Information 2012. American Society of Health-System Pharmacists.(d)Wilmes LJ; Pallavicini MG; Fleming LM; Gibbs J; Wang D; Li KL; Partridge SC; Henry RG; Shalinsky DR; Hu-Lowe D; Park JW; McShane TM; Lu Y; Brasch RC; Hylton NM (April 2007). AG-013736, A Novel Inhibitor of VEGF Receptor Tyrosine Kinases, Inhibits Breast Cancer Growth and Decreases Vascular Permeability as Detected by Dynamic Contrast-Enhanced Magnetic Resonance Imaging. Magn. Reson. Imaging 2007, 25, 319-327. [PubMed: 17371720] (e)Cockshoot ID Bicalutamide, Clinical Pharmacokinetics and Metabolism. Clin. Pharmacokinet 2004, 43, 855-878. [PubMed: 15509184] (f)Jacobson KA; Boeynaems J-M P2Y Nucleotide Receptors: Promise of Therapeutic Applications. Drug Discov. Today 2010, 15, 570-578. [PubMed: 20594935]

(4). For selected reviews on metal-catalyzed thioether synthesis, see:(a)Lee C-F; Liu Y-C; Badsara SS Transition-Metal-Catalyzed C-S Bond Coupling Reaction. Chem. Asian. J 2014, 9, 706-722. [PubMed: 24443103] (b)Eichman CC; Stambuli JP Transition Metal Catalyzed Synthesis of Aryl Sulfides. Molecules 2011, 16, 590-608. [PubMed: 21242940] (c)Beletskaya IP; Ananikov VP Transition-Metal-Catalyzed C-S, C-Se, and C-Te Bond Formation via Cross-Coupling and Atom-Economic Addition Reactions. Chem. Rev 2011, 111, 1596-1636. [PubMed: 21391564] (d)Ley SV; Thomas AW Modern Synthetic Methods for Copper-Mediated C(aryl)-O, C(aryl)-N, and C(aryl)-S Bond Formation. Angew. Chem. Int. Ed 2003, 42, 5400-5449.(e)Kondo T; Mitsudo T-A Metal-Catalyzed Carbon-Sulfur Bond Formation. Chem. Rev 2000, 100, 3205 3220. [PubMed: 11749318]

(5). For examples of $\mathrm{C}-\mathrm{S}$ bond-forming reactions from aryl (pseudo)halides catalyzed by metals other than Pd, see:(a)Oderinde MS; Frenette M; Robbins DW; Aquila B; Johannes JW Photoredox Mediated Nickel Catalyzed Cross-Coupling of Thiols With Aryl and Heteroaryl Iodides via Thiyl Radicals. J. Am. Chem. Soc 2016, 138, 1760-1763. [PubMed: 26840123] (b)Jouffroy M; Kelly CB; Molander GA Thioetherification via Photoredox/Nickel Dual Catalysis. Org. Lett 2016, 18, 876-879. [PubMed: 26852821] (c)Venkanna GT; Arman HD; Tonzetich ZJ Catalytic C-S CrossCoupling Reactions Employing Ni Complexes of Pyrrole-Based Pincer Ligands. ACS Catal 2014, 4, 2941-2950.(d)Uyeda C; Tan Y; Fu GC; Peters JC A New Family of Nucleophiles for Photoinduced, Copper-Catalyzed Cross-Couplings via Single-Electron Transfer: Reactions of Thiols with Aryl Halides Under Mild Conditions $\left(0^{\circ} \mathrm{C}\right)$. J. Am. Chem. Soc 2013, 135, 9548 9552. [PubMed: 23697882] (e)Kabir MS; Lorenz M; Van Linn ML; Namjoshi OA; Ara S; Cook JM A Very Active Cu-Catalytic System for the Synthesis of Aryl, Heteroaryl, and Vinyl Sulfides. J. Org. Chem 2010, 75, 3626-3643. [PubMed: 20429581] (f)Sperotto E; van Klink GPM; de Vries JG; van Koten G Ligand-Free Copper-Catalyzed C-S Coupling of Aryl Iodides and Thiols. J. Org. Chem 2008, 73, 5625-5628. [PubMed: 18570479] (g)Jammi S; Barua P; Rout L; Saha P; Punniyamurthy T Efficient Ligand-Free Nickel-Catalyzed C-S Cross-Coupling of Thiols with Aryl Iodides. Tetrahedron Lett 2008, 49, 1484-1487.(h)Correa A; Carril M; Bolm C IronCatalyzed S-Arylation of Thiols with Aryl Iodides. Angew. Chem. Int. Ed 2008, 47, 2880-2883. (i)Zhang Y; Ngeow KC; Ying JY The First N-Heterocyclic Carbene-Based Nickel Catalyst for C-S Coupling. Org. Lett 2007, 9, 3495-3498. [PubMed: 17676857] (j)Wong Y-C; Jayanth TT; Cheng C-H Cobalt-Catalyzed Aryl-Sulfur Bond Formation. Org. Lett 2006, 8, 5613-5616. [PubMed: 17107085]

(6). For examples of C-S bond-forming reactions from aryl (pseudo)halides catalyzed by Pd, see: (a)Scattolin T; Senol E; Yin G; Guo Q; Schoenebeck F Site-Selective C-S Bond Formation at CBr over C-OTf and C-Cl Enabled by an Air-Stable, Easily Recoverable, and Recyclable Palladium(i) Catalyst. Angew. Chem. Int. Ed 2018, 57, 12425-12429.(b)Qiao Z; Wei J; Jiang X Direct Cross-Coupling Access to Diverse Aromatic Sulfide: Palladium-Catalyzed Double C-S Bond Construction Using $\mathrm{Na}_{2} \mathrm{~S}_{2} \mathrm{O}_{3}$ as a Sulfurating Reagent. Org. Lett 2014, 16, 1212-1215. [PubMed: 24555790] (c)Mao J; Jia T; Frensch G; Walsh PJ Palladium-Catalyzed Debenzylative Cross-Coupling of Aryl Benzyl Sulfides with Aryl Bromides: Synthesis of Diaryl Sulfides. Org. Lett 2014, 16, 5304-5307. [PubMed: 25298227] (d)Valente C; Pompeo M; Sayah M; Organ MG Carbon-Heteroatom Coupling Using Pd-PEPPSI Complexes. Org. Process Res. Dev 2014, 18, 180-190.(e)Bastug G; Nolan SP Carbon-Sulfur Bond Formation Catalyzed by [Pd(IPr*OMe) (cin)Cl] (cin = cinnamyl). J. Org. Chem 2013, 78, 9303-9308. [PubMed: 23937148] (f)Teverovskiy G; Surry DS; Buchwald SL Pd-Catalyzed Synthesis of Ar-SCF 3 Compounds Under Mild Conditions. Angew. Chem. Int. Ed 2011, 53, 7312-7314.(g)Fernández-Rodríguez MA; Hartwig JF One-Pot Synthesis of Unsymmetrical Diaryl Thioethers by Palladium-Catalyzed 
Coupling of Two Aryl Bromides and a Thiol Surrogate. Chem. Eur. J 2010, 16, 2355-2359. [PubMed: 20112309] (h)Alvaro E; Hartwig JF Resting State and Elementary Steps of the Coupling of Aryl Halides with Thiols Catalyzed by Alkylbisphosphine Complexes of Palladium. J. Am. Chem. Soc 2009, 131, 7858-7868. [PubMed: 19453106] (i)Fernández-Rodríguez MA; Hartwig JF A General, Efficient, and Functional-Group-Tolerant Catalyst System for the Palladium-Catalyzed Thioetherification of Aryl Bromides and Iodides. J. Org. Chem 2009, 74, 1663-1672. [PubMed: 19154131] (j)Lee J-Y; Lee PH Palladium-Catalyzed Carbon-Sulfur CrossCoupling Reactions with Indium Tri(organothiolate) and Its Application to Sequential One-Pot Processes. J. Org. Chem 2008, 73, 7413-7416. [PubMed: 18712924] (k)Fernández-Rodríguez MA; Shen Q; Hartwig JF A General and Long-Lived Catalyst for the Palladium-Catalyzed Coupling of Aryl Halides with Thiols. J. Am. Chem. Soc 2006, 128, 2180-2181. [PubMed: 16478149] (1)Murata M; Buchwald SL A General and Efficient Method for the PalladiumCatalyzed Cross-Coupling of Thiols and Secondary Phosphines. Tetrahedron 2004, 60, $7397-$ 7403.(m)Itoh T; Mase T A General Palladium-Catalyzed Coupling of Aryl Bromides/Triflates and Thiols. Org. Lett 2004, 6, 4587-4590. [PubMed: 15548082] (n)Migita T; Shimizu T; Asami Y; Shiobara J-I; Kato Y; Kosugi M The Palladium Catalyzed Nucleophilic Substitution of Aryl Halides by Thiolate Anions. Bull. Chem. Soc. Jpn 1980, 53, 1385-1389.(o)Kosugi M; Shimizu T; Migita T Reactions of Aryl Halides with Thiolate Anions in the Presence of Catalytic Amounts of Tetrakis(Triphenylphosphine)Palladium: Preparation of Aryl Sulfides. Chem. Lett 1978, 7, 13-14.(p)Farmer J; Pompeo M; Lough AJ; Organ MG [(IPent)PdCl2(morpholine)]: A Readily Activated Precatalyst for Room-Temperature, Additive-Free Carbon-Sulfur Coupling. Chem. Eur. J 2014, 20, 15790-15798. [PubMed: 25303733] (q)Scattolin T; Senol E; Yin G; Guo Q; Shoenebeck F Site-Selective C-S Bond Formation at C-Br over C-OTf and C-Cl Enabled by an Air-Stable, Easily Recoverable, and Recyclable Palladium(i) Catalyst. Angew. Chem. Int. Ed 2018, 57, 12425-12429.

(7). For synthetic applications of stoichiometric C-S bond formation from arylpalladium complexes, see:(a)Kubota K; Dai P; Pentelute BL; Buchwald SL Palladium Oxidative Addition Complexes for Peptide and Protein Crosslinking. J. Am. Chem. Soc 2018, 140, 3128-3133. [PubMed: 29406701] (b)Rojas AJ; Zhang C; Vinogradova EV; Buchwald N; Reilly J; Pentelute BL; Buchwald SL Divergent Unprotected Peptide Macrocyclisation by Palladium-Mediated Cysteine Arylation. Chem. Sci 2017, 8, 4257-4263. [PubMed: 29081961] (c)Vinogradova EV; Zhang C; Spokoyny AM; Pentelute BL; Buchwald SL Organometallic Palladium Reagents for Cysteine Bioconjugation. Nature 2015, 526, 687-691. [PubMed: 26511579]

(8). (a)Bruno NC; Tudge MT; Buchwald SL Design and Preparation of New Palladium Precatalysts for C-C and C-N Cross-Coupling Reactions. Chem. Sci 2013, 4, 916-920. [PubMed: 23667737] (b)Martin R; Buchwald SL Palladium-Catalyzed Suzuki-Miyaura Cross-Coupling Reactions Employing Dialkylbiaryl Phosphine Ligands. Acc. Chem. Res 2008, 41, 1461-1473. [PubMed: 18620434]

(9). (a)Dennis JM; White NA; Liu RY; Buchwald SL Breaking the Base Barrier: An Electron-Deficient Palladium Catalyst Enables the Use of a Common Soluble Base in C-N Coupling. J. Am. Chem. Soc 2018, 140, 4721-4725. [PubMed: 29529363] (b)Ruiz-Castillo P; Buchwald SL Applications of Palladium-Catalyzed C-N Cross-Coupling Reactions. Chem. Rev 2016, 116, 12564-12649. [PubMed: 27689804] (c)Surry DS; Buchwald SL Dialkylbiaryl Phosphines in Pd-catalyzed Amination: a User's Guide. Chem. Sci 2011, 2, 27-50. [PubMed: 22432049]

(10). (a)Zhang H; Ruiz-Castillo P; Buchwald SL Palladium-Catalyzed C-O Cross-Coupling of Primary Alcohols. Org. Lett 2018, 20, 1580-1583. [PubMed: 29474078] (b)Cheung CW; Buchwald SL Palladium-Catalyzed Hydroxylation of Aryl and Heteroaryl Halides Enabled by the Use of a Palladacycle Precatalyst. J. Org. Chem 2014, 79, 5351-5358. [PubMed: 24762125] (c)Cheung CW; Buchwald SL Mild and General Palladium-Catalyzed Synthesis of Methyl Aryl Ethers Enabled by the Use of a Palladacycle Precatalyst. Org. Lett 2013, 15, 3998-4001. [PubMed: 23883393] (d)Wu X; Fors BP; Buchwald SL A Single Phosphine Ligand Allows Palladium-Catalyzed Intermolecular C-O Bond Formation with Secondary and Primary Alcohols. J. Am. Chem. Soc 2011, 50, 9943-9947.

(11). (a)Sather AC; Buchwald SL The Evolution of $\mathrm{Pd}(0) / \mathrm{Pd}(\mathrm{II})$-Catalyzed Aromatic Fluorination. Acc. Chem. Res 2016, 49, 2146-2157. [PubMed: 27656765] (b)Watson DA; Teverovskiy G; Zhang Y; Garcia-Fortanet J; Kinzel T; Buchwald SL Formation of ArF from LPdAr(F): Catalytic 
Conversion of Aryl Triflates to Aryl Fluorides. Science 2009, 325, 1661-1664. [PubMed: 19679769]

(12). (a)Ferguson DM; Bour JR; Canty AJ; Kampf JW; Sanford MS Stoichiometric and Catalytic Aryl-Perfluoroalkyl Coupling at Tri-tert-butylphosphine Palladium(II) Complexes. J. Am. Chem. Soc 2017, 139, 11662-11665. [PubMed: 28800228] (b)Cho EJ; Buchwald SL The PalladiumCatalyzed Trifluoromethylation of Vinyl Sulfonates. Org. Lett 2011, 13, 6552-6555. [PubMed: 22111687] (c)Cho EJ; Senecal TD; Kinzel T; Zhang Y; Watson DA; Buchwald SL The Palladium-Catalyzed Trifluoromethylation of Aryl Chlorides. Science 2010, 328, 1679-1681. [PubMed: 20576888]

(13). Ganley JM; Yeung CS Unprotected Indazoles Are Resilient to Ring-Opening Isomerization: A Case Study on Catalytic C-S Couplings in the Presence of Strong Base. J. Org. Chem 2017, 82, 13557-13562. [PubMed: 29178797]

(14). Casey ML; Kemp DS; Paul KG; Cox DD Physical Organic Chemistry of Benzisoxazoles. I. Mechanism of The Base-Catalyzed Decomposition of Benzisoxazoles. J. Org. Chem 1973, 38, 2294-2301.

(15). Ingoglia BT; Buchwald SL Oxidative Addition Complexes as Precatalysts for Cross-Coupling Reactions Requiring Extremely Bulky Biarylphosphine Ligands. Org. Lett 2017, 19, 2853-2856. [PubMed: 28498667]

(16). $\mathrm{P} 4$ and $\mathrm{P}^{*} 4$ exist in equilibrium with a dearomatized isomer, as described in the Supporting Information. For a detailed investigation of this reversible rearrangement, see:Milner PJ; Maimone TJ; Su M; Chen J; Mu P; Buchwald SL Investigating the Dearomative Rearrangement of Biaryl Phosphine- Ligated Pd (II) Complexes. J. Am. Chem. Soc 2012, 134, 19922-19934. [PubMed: 23153301]

(17). The precatalyst L4.CH2Cl2 was purchased from Strem as the dichloromethane solvate and was used as purchased.See the Supporting Information for details. 


\section{A. Previous Work}

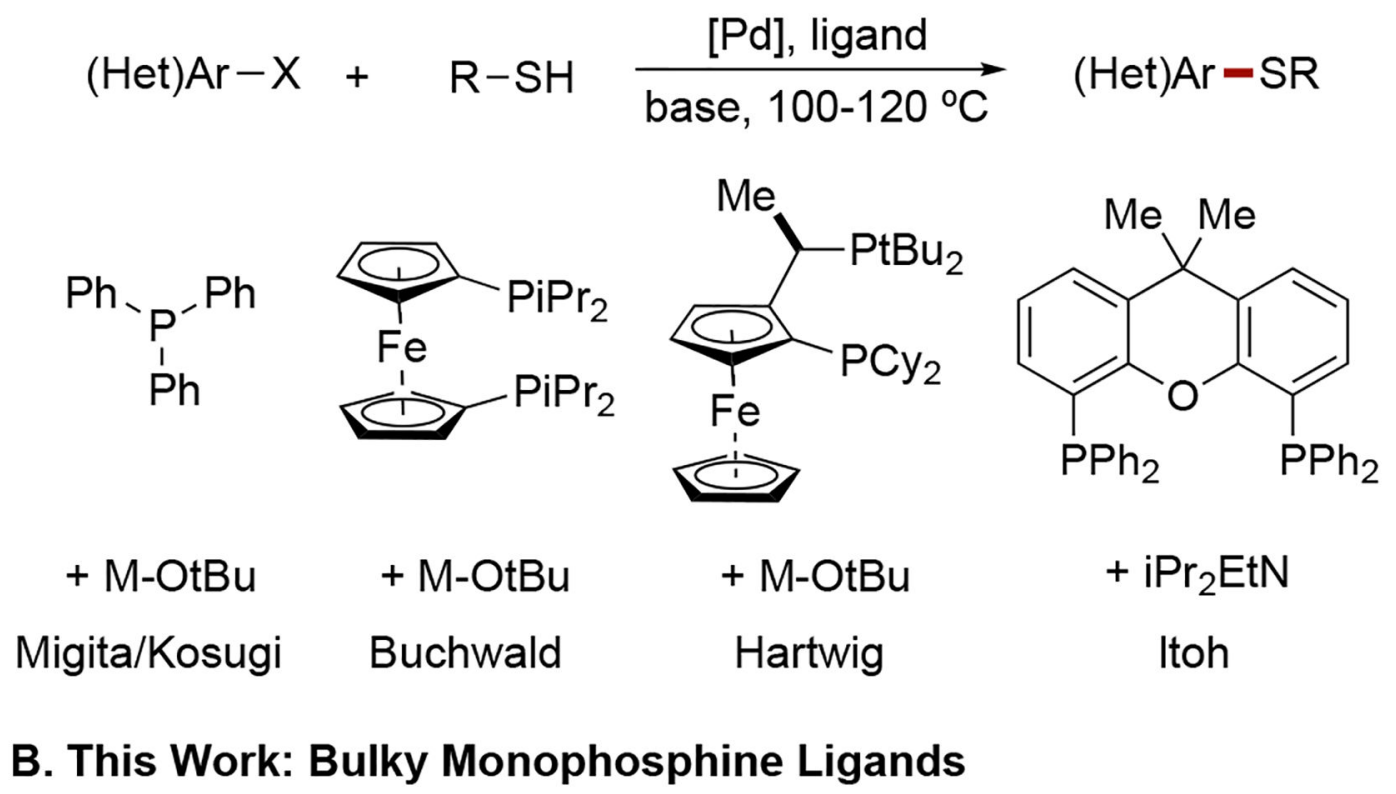

$$
(\mathrm{Het}) \mathrm{Ar}-\mathrm{Br}+\mathrm{R}-\mathrm{SH} \underset{\text { soluble base, } \mathrm{rt}}{\stackrel{[\mathrm{Pd}], \text { ligand }}{\longrightarrow}}(\mathrm{Het}) \mathrm{Ar}=\mathrm{SR}
$$

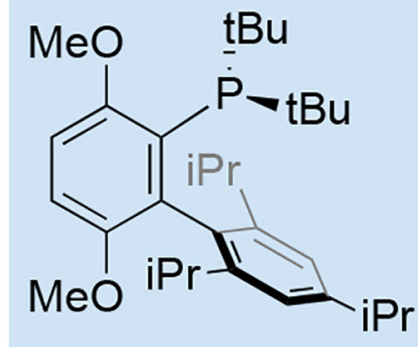

tBuBrettPhos

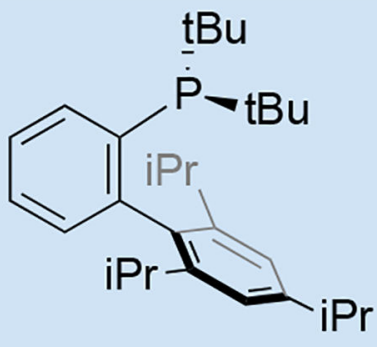

tBuXPhos

Figure 1.

Overview of phosphine ligand development for Pd-catalyzed C-S cross-coupling. 


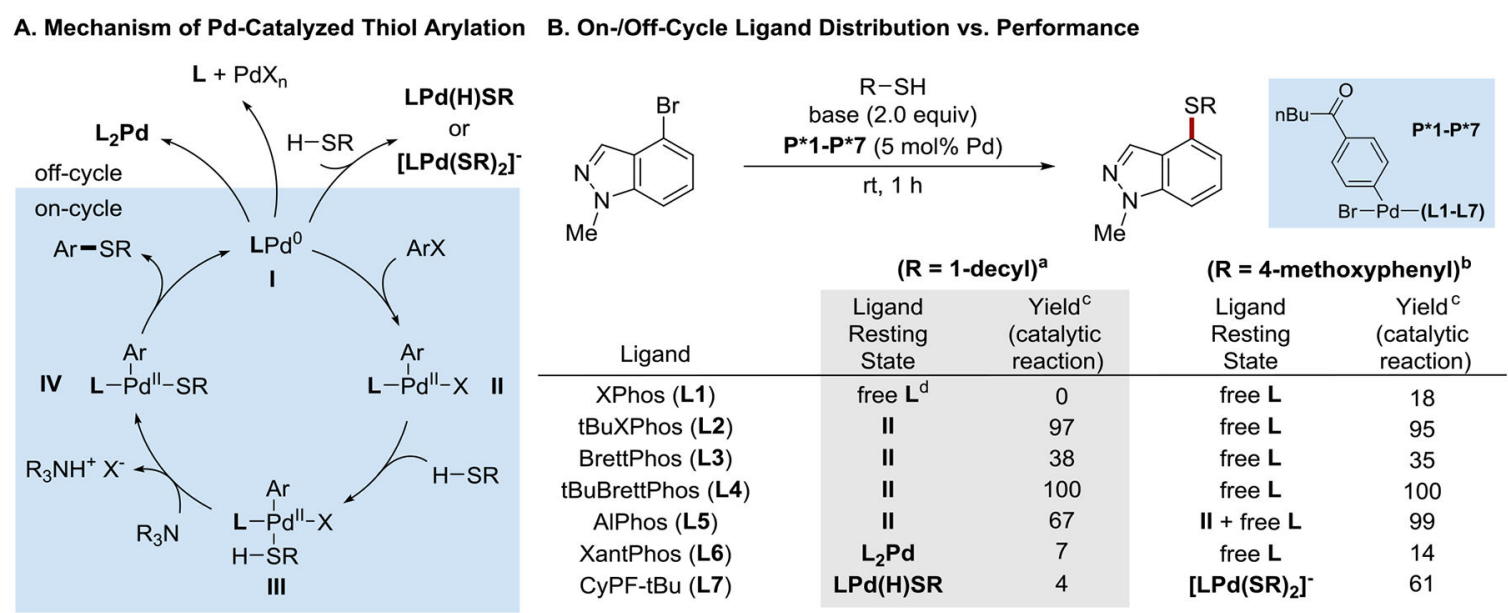

Figure 2.

Mechanistic studies. See the Supporting Information for details. ${ }^{a}$ Using triethylamine as the

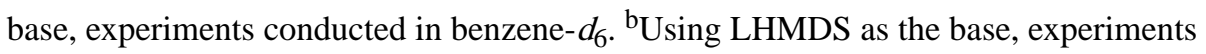
conducted in THF. ${ }^{c}$ Yield of the catalytic reaction as determined by GC after $2 \mathrm{~h} .{ }^{\mathrm{d}}$ Measured in $\mathrm{CDCl}_{3}$ rather than benzene. 
Table 1.

Evaluation of catalysts and reaction conditions for Pd-catalyzed alkyl thiol arylation. ${ }^{a}$
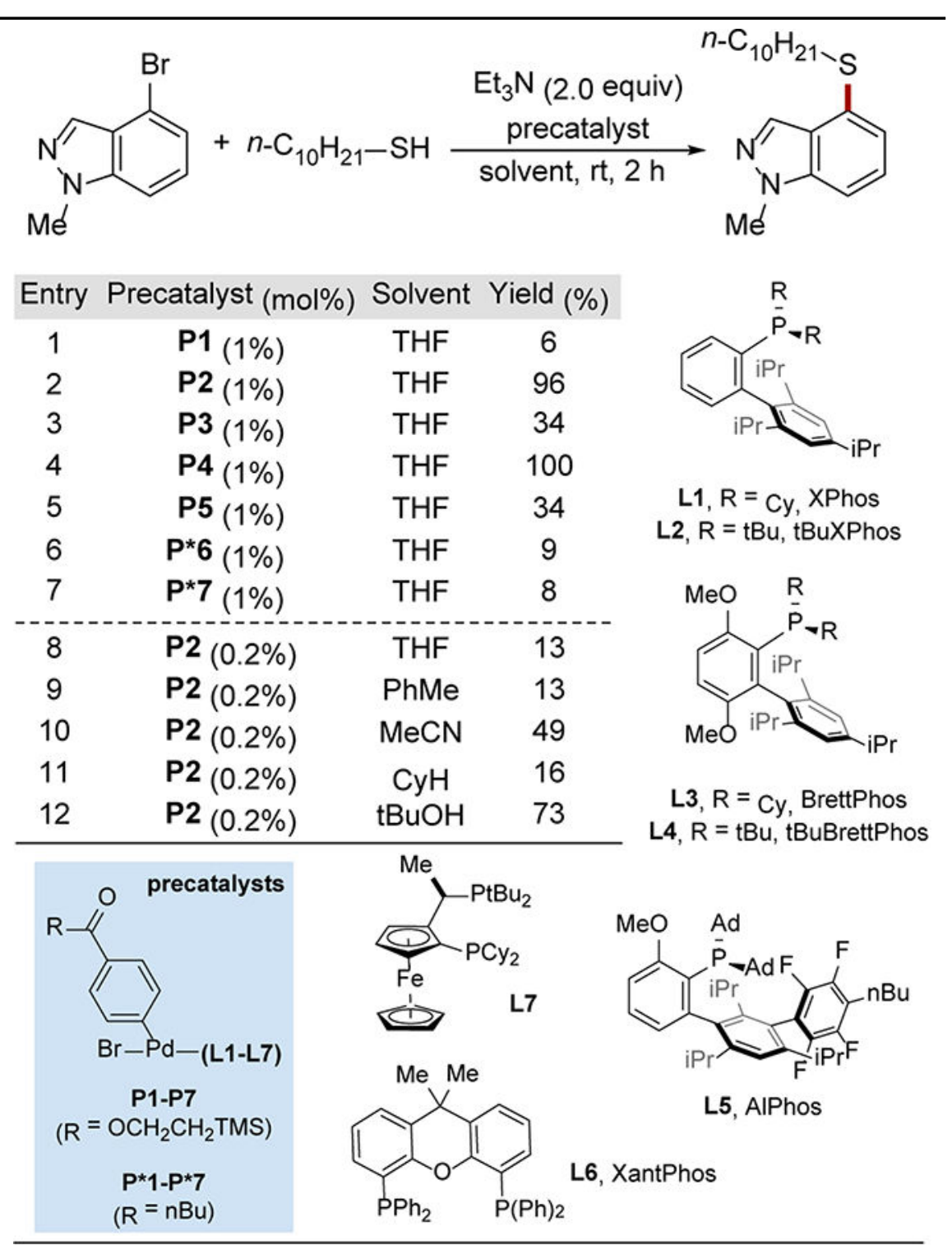

${ }^{a}$ Conditions: aryl bromide $(0.1 \mathrm{mmol}, 1.0$ equiv), thiol (1.2 equiv), triethylamine (2.0 equiv), precatalyst (indicated amount) in solvent $(0.20 \mathrm{~mL})$ for $2 \mathrm{~h}$. The yield was determined by calibrated gas chromatography (GC) using dodecane as an internal standard. See the Supporting Information for more details. 
Table 2.

Scope of the aliphatic thiol coupling reaction. ${ }^{a}$

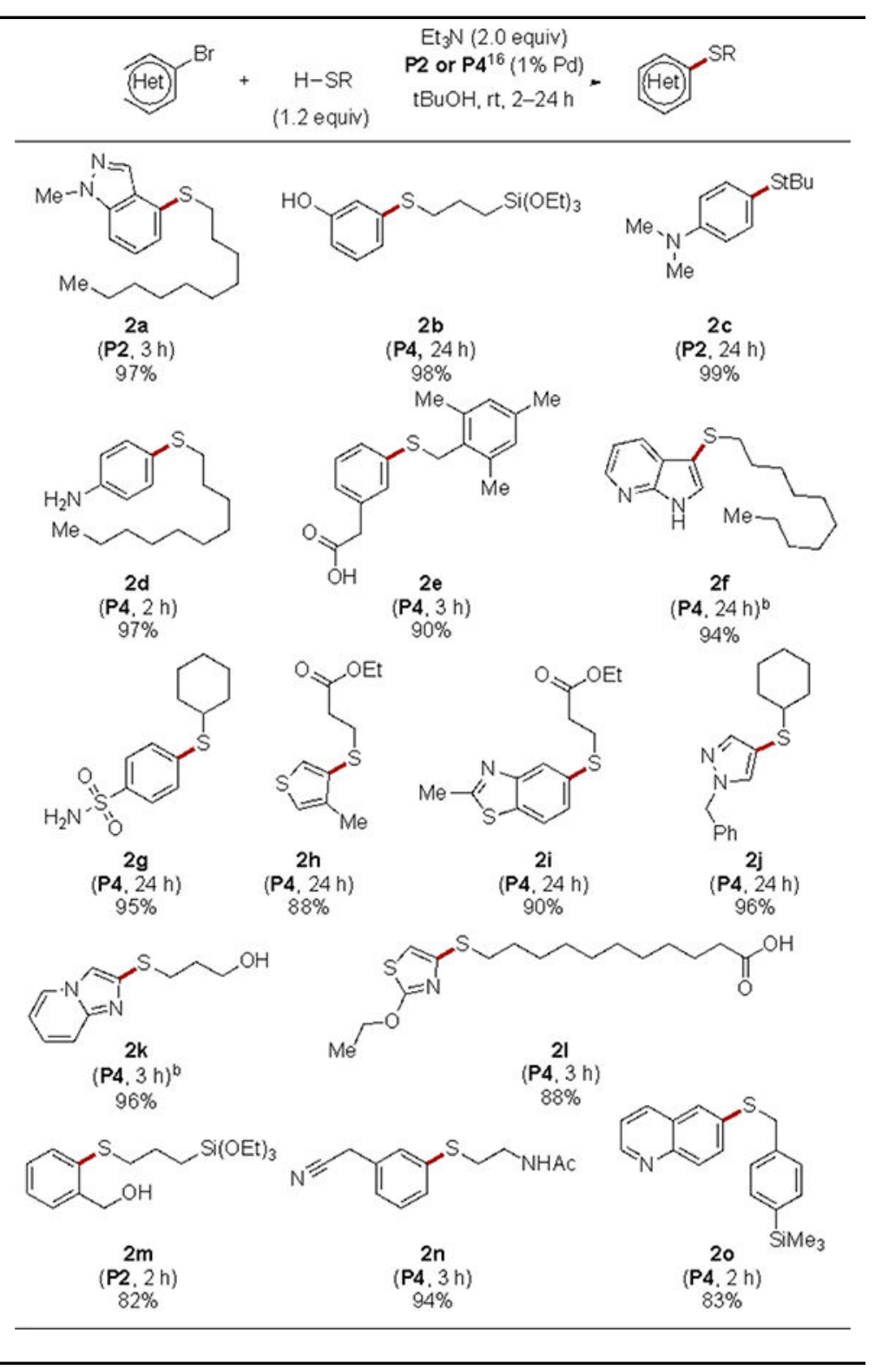

${ }^{a}$ Conditions: aryl bromide (1.0 mmol, 1.0 equiv), thiol (1.2 equiv), triethylamine (2.0 equiv), precatalyst ${ }^{16}(1 \mathrm{~mol} \%)$ in tert-butanol (2.0 mL). The precatalyst used and reaction time are indicated in parentheses. Yields represent average isolated yields from two independent replicates. For examples of reactant combinations that fail to provide useful yields of coupling product under our conditions, see table S1. See the Supporting Information for details.

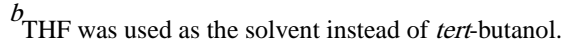


Table 3.

Scope of the aromatic thiol coupling reaction. ${ }^{a}$

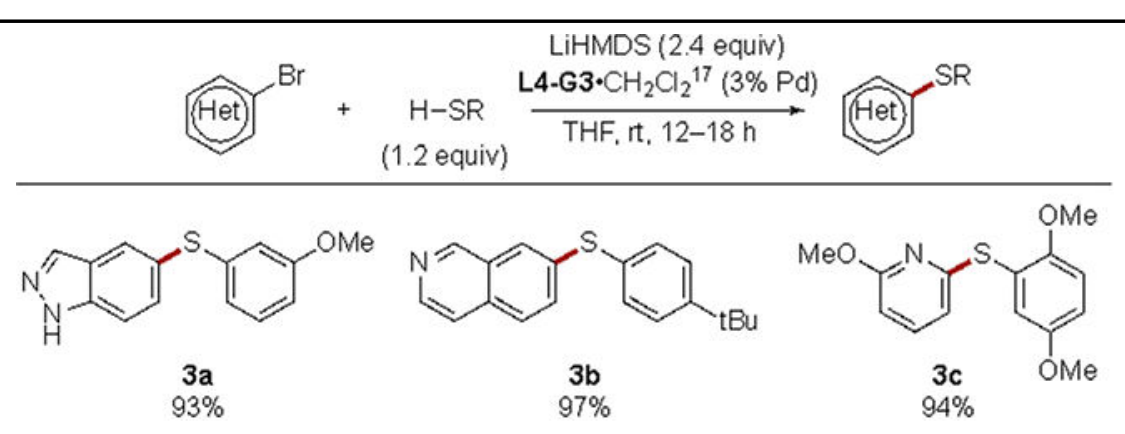<smiles>C=C/C(=C\C(=C)OC)Sc1ccccc1</smiles><smiles>COc1cccc(Sc2ccc3ccccc3c2)n1</smiles><smiles>COc1cccnc1Sc1ccccc1O</smiles><smiles>[131I-]</smiles>
$80 \%$<smiles>COc1cccnc1Sc1ccccc1F</smiles>

$3 \mathrm{j}$<smiles>COC1=NC(Sc2cccc([N+](=O)[O-])c2)CC=C1</smiles>

$3 \mathrm{~h}$

$87 \%$<smiles>COc1ccc(Sc2ncccc2OC)cc1</smiles>

$3 \mathrm{k}$

$94 \%$

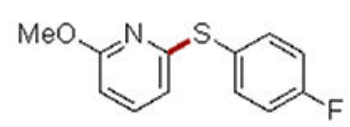

$3 i$

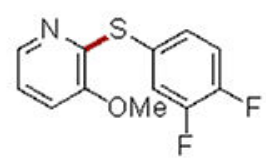

31

$94 \%$

${ }^{a}$ Conditions: aryl bromide (1.0 mmol, 1.0 equiv), thiol (1.2 equiv), LHMDS (2.4 equiv), precatalyst ${ }^{17}$ ( 3 mol $\%$ ) in THF (2.0 mL). Yields represent average isolated yields from two independent replicates. See the Supporting Information for details. 